\title{
Height systems and vertical datums: a review in the Australian context
}

W. E. Featherstone (corresponding author)

Western Australian Centre for Geodesy, Curtin University of Technology, GPO Box U1987, Perth, WA 6845, Australia; Tel: 089266 2734; Fax: 089266 2703; Email:W.Featherstone@curtin.edu.au

M. Kuhn

Western Australian Centre for Geodesy, Curtin University of Technology, GPO Box U1987, Perth, WA 6845, Australia; Tel: 089266 7603; Fax: 089266 2703; Email: M.Kuhn@curtin.edu.au

\begin{abstract}
This paper reviews (without equations) the various definitions of height systems and vertical geodetic datum surfaces, together with their practical realisation for users in Australia. Excluding geopotential numbers, a height system is a one-dimensional coordinate system used to express the metric distance (height) of a point from some reference surface. Its definition varies according to the reference surface chosen and the path along which the height is measured. A vertical geodetic datum is the practical realisation of a height system and its reference surface for users, nominally tied to mean sea level. In Australia, the normalorthometric height system is used, which is embedded in the Australian Height Datum (AHD). The AHD was realised by the adjustment of $\sim 195,000 \mathrm{~km}$ of spirit-levelling observations fixed to limited-term observations of mean sea level at multiple tide-gauges. The paper ends by giving some explanation of the problems with the AHD and of the differences between the AHD and the national geoid model, pointing out that it is preferable to recompute the AHD.
\end{abstract}

Keywords: Height systems, vertical datums, geoid, AHD, gravity, sea level

\section{INTRODUCTION}

This paper was, in part, inspired by a review of 'heights' conducted in the USA (Meyer et al., 2004; 2005) as part of its so-called height modernization programme (NGS, 1998; http://www.ngs.noaa.gov/heightmod/). Since the [Australian] Intergovernmental Committee on Surveying and Mapping (ICSM) has also embarked on a height modernisation programme 
(e.g., Johnston and Luton, 2001), it is instructive to clarify the various definitions of 'heights' in the Australian context. As well as in the USA and Australia, numerous other countries are now revisiting the definition and realisation of their respective height systems and vertical datums (e.g., Christie, 1994; Benciolini et al., 2001; Véronneau et al., 2001; Amos et al., 2005, Kingdon et al., 2005, among several others).

This review paper also builds upon previous studies related to 'heights' in Australia (e.g., Gilliland, 1986; Holloway, 1988; Mitchell, 1988; 1990; Kearsley et al., 1988; 1993; Morgan, 1992; Steed and Holtznagel, 1994; Featherstone et al., 2001). It starts with the fundamental definitions of the various height systems, classifying them into two principal groups: geometrical height systems that are not related to the Earth's gravity field; and physical/natural height systems that are fundamentally related to the Earth's gravity field. It simultaneously reviews the various vertical datum (or zero level) surfaces for these height systems and their practical point-wise realisation (cf. Vaníček, 1991; Zilkoski, 2001). Finally, the practical realisation of both the height system and vertical datum used in Australia (i.e., the Australian Height Datum (AHD); Roelse et al., 1975) is critically reviewed, with the longterm view of providing an improved vertical spatial data infrastructure to Australians.

We shall not deal with the unification of vertical datums, which has been discussed for the global case (e.g., Colombo, 1980; Rapp, 1983; 1994; 1995; Rummel and Teunissen, 1988; Rapp and Balasubramania, 1992; Xu, 1992; Balasubramania, 1994; Rummel and Ilk, 1995; Kumar and Burke, 1998; van Olsen and van Gelderen, 1998; Heck and Rummel, 1989; Pouttanen, 1999; Burša et al., 2004) and in the Australian context (e.g., Rizos et al., 1991; Featherstone, 2000; 2002a). Nor shall we deal with the time variation of sea level, gravity, height systems and vertical datums (e.g., Biró, 1983; Ekman, 1989). All these topics will be the subjects of future studies in the Australian context; once more information about the timevariability of the Earth's gravity field comes from the new dedicated satellite gravity missions (e.g., Rummel et al., 2002; Featherstone, 2002b; Tapley et al., 2004).

\section{HEIGHT SYSTEMS}

A height system is a one-dimensional coordinate system used to define the metric distance of some point from a reference surface along a well-defined path, termed simply the height of that point. While seemingly simple, the height of a point can be defined in many subtly different ways, each of which gives a different height coordinate for the same point. As such, the definition and use of the term 'height' needs great care. 
The largest influence on the adopted height is the choice of the datum surface, but it seems to be less well known that the path that the distance [height] is measured over is also a significant contributing factor. Essentially, there are two classes of height system: ones that ignore the Earth's gravity field and thus use straight-line paths; and those that are naturally linked to the equipotential surfaces and plumblines of the Earth's gravity field and thus follow curved paths.

The latter are of most practical and intuitive use. Take the following instructive example: height differences are used in engineering projects to determine the flow of fluids (e.g., a drainage system), where water is expected to flow down hill from a higher to lower height. However, it is actually the force of gravity that governs fluid flow, not height. Therefore, selection of a height system that neglects gravity, or does not use it rigorously, allows the possibility of fluids appearing to flow 'up hill'. Clearly, such a system is counterintuitive, thus reminding us that only heights properly related to the Earth's gravity field are natural and physically meaningful for most (but not all) applications.

In recent years, some authors (e.g., Steinberg and Papo, 1998; Kumar, 2005) have become proponents of purely ellipsoidal height systems, which neglect the effect of gravity. Clearly, these are unsuitable for any application that involves fluid flow in any way, among other reasons (e.g., Vaníček, 1998). However, there are cases where the use of ellipsoidal heights alone may suffice, such as the vertical component of an airborne mapping project or marine navigation where the hull/keel of a GPS-navigated ship has to clear seabed depths expressed in ellipsoidal heights. This aside, the uncontrolled use of ellipsoidal heights raises the issue of compatibility of datasets, where lay users may incorrectly integrate them with other types of height.

Throughout the sequel, all heights will be reckoned positively away from the Earth's centre of mass, with zero values at their respective datum surfaces, and negative values below.

\section{Levelling loop closures}

Historically, the most commonly used technique for the practical determination of heights is spirit levelling. This technique measures the (geometrical) height difference between two points (staves), where the reference surface is the local horizon defined by the set-up of the levelling instrument. Both staves and the levelling instrument are aligned with the direction of the local plumbline (specifically, the gravity vector) at each respective point.

Using spirit-levelling loop closures is a common and standard field-check, where the closure of the observations (e.g., the sum of 'rise and fall' height differences) is usually 
expected to indicate the quality of the observations and help detect gross errors. As well as the use of levelling loop closures being flawed (two equal and opposite gross errors in a loop will still allow that loop to close), a zero misclose is never expected in theory unless the Earth's gravity field is properly taken into account. Furthermore, the theoretical loop closure using spirit-levelling data depends on the route taken (e.g., Heiskanen and Moritz, 1967, Chapter 4).

This can be conceptualised as follows. For each set-up, the levelling instrument and staves are aligned with respect to the direction of the local gravity vector at each respective point using spirit bubbles (recall the earlier analogy of fluid flow). Each fore- and back-sight observation is essentially a geometrical measurement (here we shall ignore atmospheric refraction). Since the direction of the gravity vector varies as a function of three-dimensional position, each set up will use a slightly different vertical alignment.

These different instrumental alignments accumulate, together with the geometrical observations along the levelling loop, resulting in a misclosure. Moreover, due to the irregular mass distribution inside the Earth, the theoretically expected misclosure will change depending on the levelling route chosen. In order to avoid this situation, it is necessary to apply corrections (described later) for the gravity-related misalignment of the instrument and staves in order for the loop to theoretically close (under the assumption of no measurement errors). However, this is not necessary for purely geometric heights (see ellipsoidal heights below) that do not relate to the Earth' gravity field. As such, zero loop closures for ellipsoidal heights derived from GPS surveys can be expected in theory, but not in practice because of the intrinsically weaker height measurement from GPS (i.e., larger errors).

In the Australian context, it is worth commenting that most spirit-levelling observations have been or are conducted to Australian class LC tolerances (ICSM, 2002), which permit a loop misclose of $12 \sqrt{k} \mathrm{~mm}$, where $k$ is the distance levelled in kilometres. These are also called third-order tolerances (e.g., Leppert, 1967; Morgan, 1992). This class LC tolerance is greater than the error that would be introduced by neglecting the corrections for gravity (especially in the east-west direction), but these corrections cannot be neglected for class L1A observations (ICSM, 2002). A point of concern in this regard is that the formulas to be used in Australia for these corrections are not routinely supplied, leaving the surveyor to decipher and apply the gravity-related correction in Roelse et al. (1975). It is also worth noting that the gravity-related corrections are systematic, whereas closure tolerances tend to assume random errors. 


\section{Height Systems Not Related to Gravity: Ellipsoidal Heights}

It is conceptually simpler to first deal with purely geometrical height systems, where the heights are measured along straight lines. The most common geodetic height system not directly related to gravity is the ellipsoidal height system. We say not directly because sometimes the reference ellipsoid is defined to generate its own gravity field (described later). However, this plays no role in the purely geometrical definition of the ellipsoidal height system.

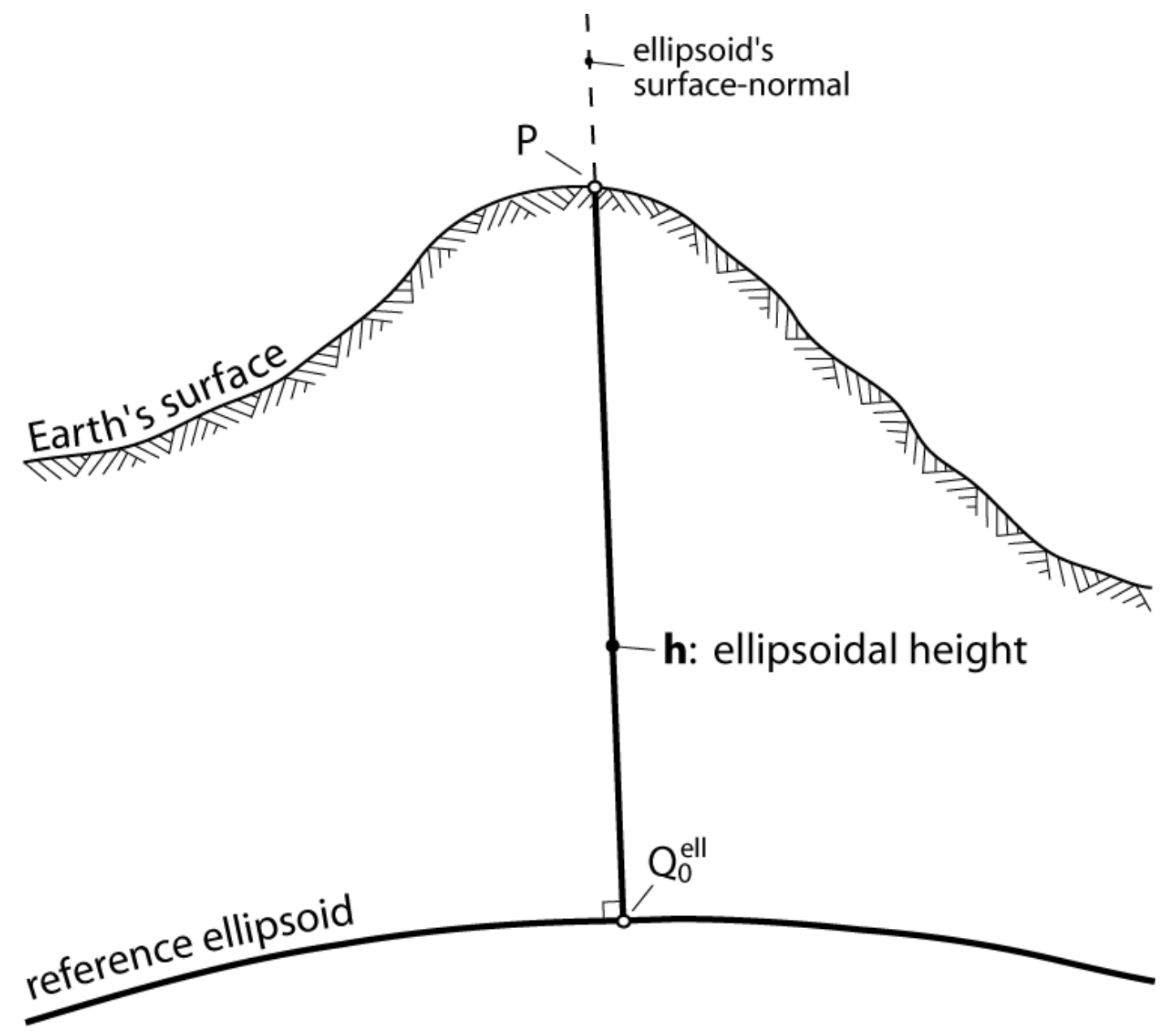

Figure 1. The ellipsoidal height $\mathbf{h}$ : a straight-line distance reckoned along the ellipsoidal normal from the point $Q_{0}^{\text {ell }}$ on the surface of a reference ellipsoid to the point of interest $P$

The ellipsoidal height is a straight-line distance reckoned along the ellipsoidal normal from the geometrical surface of a reference ellipsoid to the point of interest (Figure 1). Since 
this is a one-to-one mapping, this height is unique to each 2D point (latitude and longitude on the same ellipsoid), thus permitting a unique 3D [curvilinear] coordinate system. This is the well-known geodetic coordinate system. The geometrical surface of the ellipsoid provides the height reference surface by definition, on which the ellipsoidal heights are zero. As such, the numerical value of the ellipsoidal height of a point is a function of the location, orientation, size and shape of the reference ellipsoid used. Since there are several ellipsoids in use, classifiable as global and local/regional (e.g., Featherstone, 1996), the same point can have different ellipsoidal heights on different ellipsoids, just as it can have different latitudes and longitudes. Accordingly, it is important to specify the ellipsoid used when dealing with ellipsoidal heights.

In the Australian context, ellipsoidal heights can refer to the old Australian National Spheroid (ANS; Bomford, 1967) or the Geodetic Reference System 1980 (GRS80; Moritz, 1980) reference ellipsoid, which is equal to the World Geodetic System 1984 (WGS84; NIMA, 2004) reference ellipsoid at the $0.1 \mathrm{~mm}$ level. Importantly, ANS and GRS80 ellipsoidal heights are not equal, and can differ for the same point by up to as much as $\sim 75 \mathrm{~m}$ because of the different size, shape and orientation (regional or geocentric) of these ellipsoids. The value of $75 \mathrm{~m}$ is estimated from the geoid-GRS80-ellipsoid separation (Featherstone et al., 2001) assuming that the ANS is coincident with the geoid, which it is to less than $\sim 10 \mathrm{~m}$. As such, Australian users dealing with ellipsoidal heights need to know to what reference surface they apply: the ANS or GRS80/WGS84. Later, it will be shown that the datum is also essential information that must accompany ellipsoidal heights.

\section{Height Systems Related to Gravity: Natural or Physical Heights}

These height systems come in several forms, depending principally on the treatment of gravity and thus the curved path over which the one-dimensional metric distance (height) is defined. They also depend on the choice of the reference surface used, though this is not as noticeable as it is for the ellipsoidal heights (e.g., maximum differences of $\sim 2 \mathrm{~m}$ ). As a primer on natural/physical height systems in the Earth's gravity field, the more mathematically inclined reader is referred to Heiskanen and Moritz (1967, Chapter 4), Heck (1995) and Jekeli (2000). Other geodetic textbooks (e.g., Bomford, 1980; Vaníček and Krakiwsky, 1986; Torge, 2001) also give explanations of natural/physical height systems.

Geopotential Numbers Strictly, all natural or physical height systems must be based on geopotential numbers $C$. A geopotential number is the difference between the Earth's gravity 
potential at the point of interest $W$ and that on the reference geopotential surface chosen $W_{0}$ (i.e., $C=W-W_{0}$ ). Unrestricted fluids flow from points with higher potential energy to points with lower potential energy, where the potential energy is converted to kinetic energy (i.e., the speed of the fluid's flow). The same principle applies, more noticeably, to a skydiver! As such, geopotential numbers govern fluid flow, thus forming the logical basis for physically meaningful and conceptually sensible heights.

However, the use of geopotential numbers alone is counter-intuitive because they have the dimensions of length-squared divided by time-squared. As such, it is preferable to express them in the more intuitive terms of height in dimensions of length. This is achieved by dividing the [negative value of the] geopotential number by some value of gravity (dimension of length divided by time-squared). All the following natural/physical height systems are based on this principle. Another objection to the use of geopotential numbers alone is that they cannot be observed directly: there is currently no field instrument that directly measures gravity potential.

Instead, spirit-levelling measurements have to be supplemented by gravity observations along the traverses to determine the gravity potential differences, and hence the geopotential numbers. Obviously, this increases field-survey effort and cost. Nevertheless, geopotential numbers (essentially gravity potential differences) strictly govern fluid flow and are thus a truly rigorous expression of 'heights', with the only objection being that they do not represent metric distances. Finally, geopotential numbers provide a theoretical zero misclose regardless of what spirit-levelling route has been taken. As such, height systems based on them and with the proper treatment of gravity will also theoretically close (with error-free measurements); see Sansò and Vaníček (2005) for a theoretical discussion on this point.

From the above discussion, the key elements to defining a natural/physical height system are the definitions of gravity and the reference geopotential surface $W_{0}$. Over the past two centuries, three natural height systems have been proposed (e.g., Heiskanen and Moritz, 1967, Chapter 4): dynamic heights, orthometric heights and normal heights. More recently, a fourth height system has been introduced: normal-orthometric heights, which combine some of the concepts of orthometric and normal heights. For the practical realisation of each height system, various levels of approximation and hence rigour have been used, which will be discussed next.

The Dynamic Height System The dynamic height system is most closely related to the system of geopotential numbers. Prior to the introduction of the geopotential number, the 
dynamic height system proposed by Helmert (1884) was in use. Dividing the geopotential number by a constant gravity value (for a certain region, or even globally) yields the dynamic height (e.g., Heiskanen and Moritz, 1967, Chapter 4). Most often, a gravity value at midlatitude $\left( \pm 45^{\circ}\right)$ has been taken as the global value, such as that generated by the reference ellipsoid.

Since the geopotential number is divided by a constant value, dynamic heights retain the same characteristics except that they have the dimension of length. Importantly, the flow of fluids is guaranteed from a greater to a lower height, and the theoretical loop closure is zero regardless of the chosen path. However, the dynamic height system is not always preferable as a practical height system because it has no geometrical meaning, being a purely physical quantity (e.g., Heiskanen and Moritz, 1967; Jekeli, 2000). This objection to the dynamic height is because the height changes with variations in gravity, as indeed it should, and the unit of length measurement is not generally the same as, for instance, the metre as endorsed by the ISO (international standards organisation).

Furthermore, the dynamic height corrections to be applied to spirit-levelled height differences can become very large (several metres) if the chosen gravity value is not representative for the region of operation (e.g., Torge, 2001), which would be the case for a continent the size of Australia. As such, it is preferable to use a better approximation for practical applications.

The Orthometric Height System The orthometric height is given by the geopotential number divided by the integral mean value of gravity taken along the plumbline. Unlike the dynamic height, the orthometric height $\left(H^{O}\right)$ has a clearer geometrical interpretation. It is the curved-line distance reckoned along the plumbline (field-line of the Earth's gravity field) from the geoid to the point of interest (Figure 2). The geoid reference surface is also unique, being the single equipotential surface of the Earth's gravity field that broadly corresponds with mean sea level in the open oceans. More strictly, however, it is defined by $W_{0}=$ constant. 


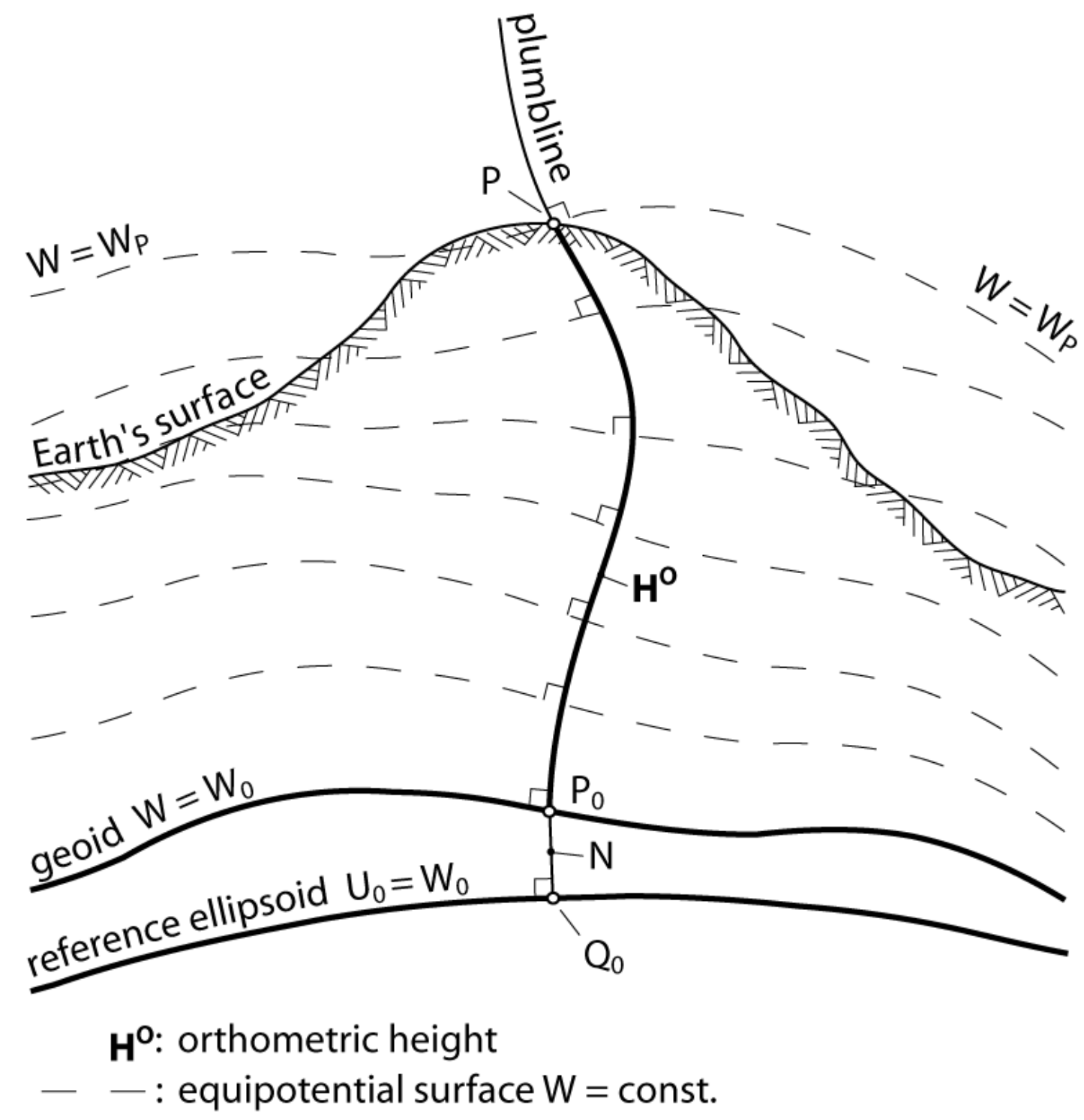

Figure 2. The orthometric height $\mathbf{H}^{\mathbf{o}}$ : a curved-line distance reckoned along the plumbline from the point $P_{0}$ on the surface of the geoid to the point of interest $P$. The geoid height $N$ : a straight line distance reckoned along the ellipsoidal surface normal from the point $Q_{0}$ on the surface of the ellipsoid to the point $P_{0}$ on the surface of the geoid (Note that the curvature of the equipotential surfaces and plumblines has been exaggerated)

The orthometric height system is hard to realise perfectly in practice, because we need to know the exact path of the plumbline within the topography and the Earth's gravity acceleration at all points along the plumbline. This requires knowledge of gravity variations (cf. Strange, 1982) or mass-density distribution (cf. Sünkel, 1986; Allister and Featherstone, 2001) inside the topography. It is therefore essential to realise that a completely 'pure' orthometric height system cannot yet be achieved, and is unlikely to be so in the foreseeable 
future. This is because the mass-density distribution will not be completely known and it is not practical/possible to measure gravity along the plumbline within the topography.

Most countries that claim to use an orthometric height system actually use Helmert's (1890) approximation, where a number of simplifying hypotheses are made concerning the gravity field inside the topography. To determine a Helmert orthometric height, a surface gravity observation at the point of interest is approximately converted to an integral-mean value along the plumbline using the simplified Poincaré-Prey reduction (e.g., Heiskanen and Moritz, 1967, Chapter 4). This reduction crudely approximates the vertical gravity gradient by the linear free-air gradient and models the topography by a spherical shell with a constant mass-density of $2670 \mathrm{~kg} / \mathrm{m}^{3}$. The Helmert mean value of gravity along the plumbline uses the Poincaré-Prey reduction to reduce surface gravity to half the station height. This approximated integral-mean gravity value can be applied to the geopotential number (if available) to give the Helmert orthometric height. More practically, a Helmert orthometric correction can be calculated (e.g., Heiskanen and Moritz, 1967, Chapter 4; Torge, 2001) and applied to spirit-levelled height differences, which also requires that gravity observations be made along the spirit-levelling traverses.

Several refinements have been proposed to the Helmert orthometric height system, where improved models for the value of integral-mean gravity along the plumbline are used. These models essentially use more refined terrain-shape data to give refined estimates of the internal gravity field (e.g., Niethammer, 1932; Mader, 1954). They may also use simplified mass-density models of the topography (e.g., Sünkel, 1986; Allister and Featherstone, 2001; Tenzer et al., 2005). Using a simulated Everest-sized mountain of constant mass-density, where the gravity field was completely known, Dennis and Featherstone (2003) show that the Mader and Neithammar heights are superior to Helmert orthometric heights (they did not consider Tenzer et al. (2005)). Notably the differences between refined and Helmert orthometric heights can amount to more than $10 \mathrm{~cm}$ in mountainous regions (Kingdon et al., 2005). However, these refined models of the orthometric height system are very rarely used in practice. Instead, the Helmert orthometric height system is still in wide use, probably due to its relative ease of implementation.

Finally, since a 'pure' orthometric height cannot be practically realised, the approximation given by the Helmert orthometric heights is most commonly used. As such, users should be wary when presented with so-called orthometric heights; they will not be. Instead, the supplier should be asked to more clearly define the height system used (e.g., which approximations have been used). Indeed, this incorrect terminology has been 
proliferated in Australia, where AHD heights have incorrectly been called orthometric heights; simply they are not. They do not relate to any field observations of the Australian gravity field.

The Normal Height System To circumvent the problem of determining the integral-mean value of actual gravity along the plumbline, in 1945 Molodensky [cf. Molodensky et al. (1962)] introduced the concept of the normal height system. The key differences from the orthometric height system are: the avoidance of hypotheses to determine the gravity field inside the topography; the theoretical replacement of the Earth's surface by the telluroid; and the use of a reference ellipsoid with associated gravity field (e.g., Heiskanen and Moritz, 1967, Chapter 8; Vaníček and Krakiwsky, 1986; Jekeli, 2000; Torge, 2001). As the mathematical derivations of Molodensky's theory are rather complicated (e.g., Heiskanen and Moritz, 1967), only the most important properties of the normal height system are reviewed below. The more interested reader is referred to the above-cited references.

The telluroid is an auxiliary surface obtained by the point-wise projection of points $P$ on the Earth's surface along the straight-line ellipsoidal normal to points $Q$ that have the same gravity potential value in the normal gravity field $U_{Q}$ as the original points $P$ in the Earth's gravity field $W_{P}$, i.e., $U_{Q}=W_{P}$ (Figure 3 ). As such, the telluroid is not an equipotenial surface. The normal gravity field $U$ is an approximation of the real Earth's gravity field $W$ and conceptually generated by masses within a reference ellipsoid (e.g., Moritz, 1980, 1992). Furthermore, the surface of the reference ellipsoid is chosen in the way that it is a normal equipotential surface and has the same normal gravity potential value as the geoid surface with respect to the Earth's gravity field, i.e. $U_{0}=W_{0}$ (Figure 3 ). 


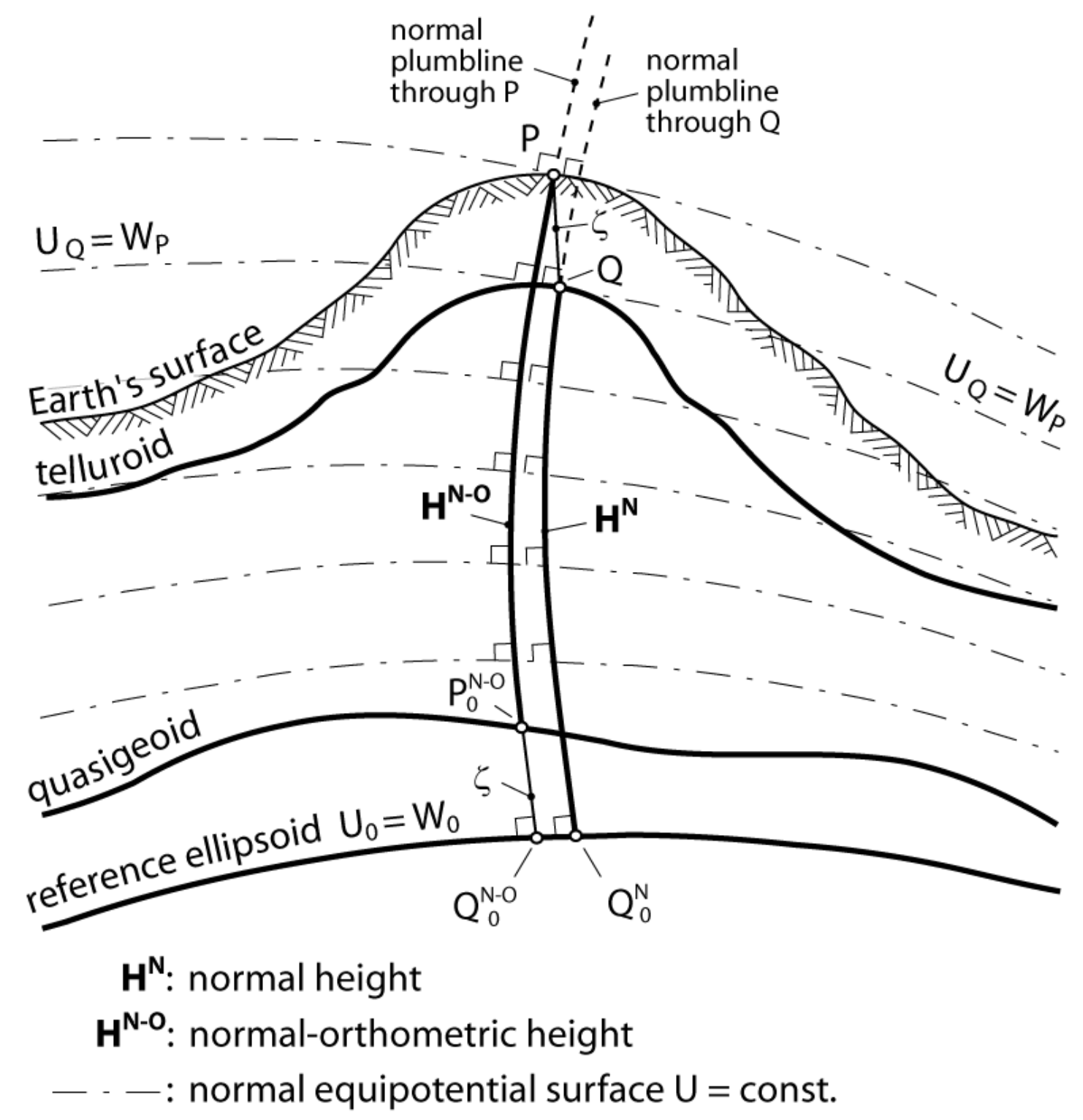

Figure 3. The normal height $\mathbf{H}^{\mathbf{N}}$ : a curved-line distance reckoned along the normal gravity plumbline from the point $Q_{0}^{\mathrm{N}}$ on the surface of the reference ellipsoid to the point $Q$ on the surface of the telluroid. The normal-orthometric height $\mathbf{H}^{\mathrm{N}-\mathrm{O}}$ : a curved-line distance reckoned along the normal gravity plumbline from the point $P_{0}^{\mathrm{N}-\mathrm{O}}$ on the surface of the quasigeoid to the point $P$ on the surface of the Earth. The quasigeoid height $\zeta$ : the straight-line distance reckoned along the ellipsoidal surface normal from the point $Q_{0}^{\mathrm{N}-\mathrm{O}}$ on the surface of the ellipsoid to the point $P_{0}^{\mathrm{N}-\mathrm{O}}$ on the surface of the quasigeoid has, by definition, the same length as the height anomaly $\zeta$ : the straight-line distance reckoned along the ellipsoidal normal from the point $P$ on the Earth's surface to the point $Q$ on the surface of the telluroid.

The distance (measured along the straight-line ellipsoidal normal) between the Earth's surface and the telluroid is called the height anomaly $(\zeta)$ and, the distance (measured along the 
curved normal gravity plumbline; Jekeli, 2000) between the ellipsoid surface and the projected point on the telluroid is the normal height $\left(H^{N}\right)$. For illustrative purposes, this relation is usually reversed (Figure 3). In this conceptualisation, the height anomaly becomes the separation between the ellipsoid and the quasigeoid (measured along the ellipsoidal normal) and the normal height is now the distance between the quasigeoid and the point of interest (measured along the normal gravity plumbline). Note that the height anomaly and quasigeoid height are the same, but the different terminology is used to reflect the different conceptualisations in Figure 3.

The quasigeoid is a non-equipotential surface of the Earth's gravity field that coincides reasonably closely with the geoid; up to about $3.4 \mathrm{~m}$ in the Himalayas (e.g., Rapp, 1997). In the Australian context this may reach 0.15m (Featherstone and Kirby, 1998). However, in order to avoid confusion with the normal-orthometric height (defined next) the former telluroid-based interpretation is retained in the following discussion.

Applying the general concept of a natural/physical height system (geopotential number divided by a gravity value) the normal height is obtained by using the integral-mean value of normal gravity taken along the normal plumbline between the ellipsoid surface and the projected point on the telluroid, which is simple to compute and does not use any topographic mass-density data. Furthermore, here the geopotential number is the gravity potential difference between the potential values on the ellipsoid surface and the telluroid. Due to the special selection of the normal gravity field (see above), this is exactly the same as the geopotential number obtained for the point of interest $\left(C=W_{P}-W_{0}=U_{Q}-U_{0}\right)$, and thus it can be derived from actual gravity observations. Importantly, the normal plumbline is the [curved] field line of the normal gravity field and does not coincide with the ellipsoidal normal (see the Introduction of Jekeli, 1999). The normal gravity field lines are curved only in the meridian plane because of the rotational symmetry of the normal gravity field.

Dealing now with the conceptual problems associated with the normal height system, the spatial variations in the Earth's gravity vector are only modelled very simplistically by the normal gravity field generated by the reference ellipsoid (e.g., Moritz, 1980, 1992). As such, the normal height system is less applicable to the real Earth than, say, the orthometric height. While the actual gravity vector varies as a function of 3D position, normal gravity only varies as a function of ellipsoidal height and geodetic latitude (Moritz, 1980). It cannot accurately model the real gravity field of the Earth, with differences amounting to a few hundred milliGal. On the other hand, as the normal gravity field is well defined, the integral-mean value of normal gravity along the normal plumbline can be determined knowing the position 
(notably only the latitude) of the point of interest. However, due to the dependency on the normal height itself (the point on the telluroid is initially unknown) the determination becomes iterative (e.g., Heiskanen and Moritz 1967, Chapter 4).

In practice, like orthometric heights, normal heights are computed from spirit-levelled height differences using the normal correction (e.g., Heiskanen and Moritz, 1967, Chapter 4; Torge, 2001). Importantly, this also requires that gravity observations be made at a sufficiently dense spacing along the spirit-levelling traverse. Over short distances, the normal corrections are usually very small and may be neglected, depending on the precision of the spirit-levelling data.

The Normal-Orthometric Height System Both orthometric and normal height systems require actual gravity observations to be taken along the levelling traverse in order to derive the geopotential numbers (or the orthometric or normal corrections). Due to the lack of precise gravimeters (before the 1950s), as well as the relatively labour-intensive nature of making gravity observations in the field, the normal-orthometric height system was introduced and adopted as a surrogate. This height system uses only the normal gravity field as an approximation of the Earth's gravity field to derive all necessary gravity-field-related quantities. Principally, actual geopotential numbers are replaced by differences in the corresponding normal potential (called normal-geopotential or spheropotential numbers) and actual gravity is replaced by normal gravity. The great advantage is the avoidance of making gravity observations, but this is at the expense of losing information of the real Earth's gravity field. Another, albeit lesser, benefit is that only latitudes are needed along the levelling line.

The geometric interpretation of the normal-orthometric height is analogous with that of the normal height, except that the relations are reversed (Figure 3). The height anomaly becomes the separation between the reference ellipsoid and the quasigeoid (measured along the ellipsoid normal) and the normal-orthometric height is now the distance between the quasigeoid and the point of interest (measured along the normal plumbline). Following this interpretation, the reference surface for the normal-orthometric height is the quasigeoid and it can be seen that the normal-orthometric height follows exactly the same principles of orthometric heights, except that all quantities of the Earth's gravity field are replaced by the corresponding quantities of the normal gravity field, hence the name normal-orthometric height.

Following this approach, the normal-orthometric height is obtained by the normalgeopotential (spheropotential) number divided by the integral-mean value of normal gravity 
taken along the normal plumbline between the quasigeoid and the point of interest. Note the distinction from the normal height, where the integral mean normal gravity is taken between the ellipsoid and telluroid and the spheropotential number replaces the geopotential number. Finally, normal-orthometric heights can be computed in practice from spirit-levelled height differences using the normal-orthometric correction (e.g., Heck, 1995; Torge, 2001). Because of the rotational symmetry of the reference ellipsoid, normal-orthometric corrections only apply to north-south levelling lines, and are zero for east-west levelling lines. Once again, the normal-orthometric corrections are usually negligible for spirit-levelling data over short distances.

\section{Summary}

This section has defined and described various height systems. Of them, only the dynamic height system is physical-geodetically rigorous because it accurately describes fluid flow in the Earth's gravity field. The other height systems are successive approximations, starting from orthometric heights and ending with uncorrected spirit-levelled heights. Note that dynamic, orthometric and normal heights use the geopotential number. Therefore, from the theoretical point of view, these heights will have a zero misclosure irrespective of the levelling path taken, provided that rigorous gravity corrections are used. This, however, does not hold for any approximations of these heights (e.g., Helmert orthometric heights), nor does it hold for the normal-orthometric heights that use the spheropotential number instead of the actual geopotential number. Thus, these approximated heights will always have a theoretical loop misclosure and, more importantly, are dependent on the levelling route taken.

\section{VERTICAL GEODETIC DATUMS}

Once the height system has been selected, which is usually the mandate of the national mapping agency, and the appropriate 'corrections' made to spirit-levelling observations, it is necessary to perform a least-squares adjustment of the corrected height differences so as to minimise the impact of random errors. Ideally, the adjustment should be performed on the geopotential numbers or height systems that have a theoretical zero misclosure (cf. Sansò and Vaníček, 2005). Otherwise, the least squares adjustment will not be applicable because it is based on the assumption of random errors, whereas the theoretical misclosures of an imperfect height system are systematic, thus violating the principles upon which a leastsquares adjustment is based. 
The results of the least-squares adjustment form the 'definitive' height values of all ground-monumented benchmarks. It is these adjusted height coordinates and benchmarks that then define the vertical datum. As such, it is a point-wise realisation of the vertical datum, as opposed to the definition of a reference surface, though the latter is often used for conceptualisation. Obviously, the vertical datum will be different depending on the choice of height system and reference surface adopted. The datum "surface" will be discussed later.

This adjustment results in a vertical geodetic datum where the heights of the benchmarks are adopted at a particular epoch of adjustment, as for a horizontal geodetic datum (cf. Featherstone, 1996). Recall that here we neglect temporal changes in sea level, height and gravity. In the case of the AHD, no such variations were assumed and the observations collected over the preceding years (see Lines (1992) and Rolese et al. (1975) for the time-evolution of the spirit-levelling coverage) were implicitly assumed to refer to a single epoch. The epoch of the AHD is effectively 5 May 1971 (Roelse et al., 1975), though the date is rarely appended (i.e., AHD71) because this was the only nation-wide adjustment conducted. Other localised adjustments have been made since to correct for gross errors, when detected, but these are still generally designated AHD. Of course, if a new AHD is realised, which these authors are strong proponents of, then a different acronym should be adopted (e.g., VDA08), together with some logical system for identifying localised readjustments.

The selection of the height system used in a vertical datum can be somewhat arbitrary, and seems to have depended on the proponents of a particular height system at the time in each country. The selection was also governed by the existing or likely future data availability at the time. For instance, to establish a Helmert orthometric height system, spiritlevelling, 2D positional and gravity observations need to be conducted; to establish a normal height system, spirit-levelling, 1D positional (latitude) and gravity observations are needed; to establish a normal-orthometric height system, only spirit-levelling and latitude observations are needed; to establish an ellipsoidal height system, only space-geodetic observations (e.g., GPS) are needed. As argued earlier, the latter is not advised because of the very compelling arguments in favour of managing fluid flow (who would want a sewerage system designed based on an ellipsoidal height datum?)

Associated with the selection of the height system is the selection of the compatible reference surface on which the height is zero. Recall that the orthometric height system uses the geoid, the normal height system the telluroid, the normal-orthometric height system the quasigeoid, and the ellipsoidal height system the reference ellipsoid. The latter further 
depends on the use of a local or global ellipsoid (e.g. ANS or GRS80; Featherstone, 1996), as well as when the ellipsoid was defined. For instance, there are the GRS67 (IAG, 1967) and GRS80 (Moritz, 1980) global geocentric reference ellipsoids with different geometries (as well as different normal gravity fields). The choice of reference ellipsoid is simple to make, but the epoch of the adjustment to form the ellipsoidal height datum still needs to be defined, which will be described later. In the case of the quasigeoid and geoid, these datum levels have to be observed indirectly, which will be described next.

\section{Vertical Geodetic Datums Related to Gravity: Geoid and Quasigeoid}

A key problem in realising the datum (zero height) surface for the natural/physical height systems is the practical determination of the geoid or quasigeoid. Recall that there is currently no instrument that can directly measure absolute values of the Earth's gravity potential. Instead, we have to make assumptions about the relationship between the geoid and mean sea level (MSL), hence assuming a value of $W_{0}$ for the particular vertical datum. Over the oceans, the geoid and quasigeoid are coincident by definition, so the following discussion will only concentrate on the practical realisation of the geoid as the zero point for the local vertical datum. Recalling the loose definition of the geoid as the equipotential surface of the Earth's gravity field that generally corresponds with MSL in the open oceans, the most logical choice has been to make tide-gauge observations of sea level. However, this introduces two further issues: 1) the determination of MSL in the presence of tides and other temporal changes in sea level, and 2) the effect of sea surface topography (SSTop) and related biases; all are particularly problematic in the coastal zone (e.g., Merry and Vaníček, 1983; Hipkin, 2000).

To correctly determine MSL at a coastal tide-gauge needs regular and uninterrupted observation of the full tidal signature. While the combination [superposition] of the relative motion of the Sun and Moon with respect to the Earth cause noticeable tides at the coast, the [smaller] effects of the precession and nutation of the Earth-Sun-Moon system cause the socalled luni-solar tide, which has a full period of 18.6 years (e.g., Melchior, 1981). As such, it is necessary to make regular (e.g., hourly) tide-gauge observations of sea level over at least the entire 18.6-year period of this luni-solar tidal cycle. However, this length of observation is rarely practical in relation to the demand for a vertical datum (e.g., Lines, 1992; Roelse et al., 1971). Depending on the time period over which the tide-gauge observations were averaged, this luni-solar tidal effect may reach several centimetres, also depending on position because tides are not everywhere equal in phase and amplitude. 
Even if the full tidal cycle were to have been observed, a more problematic effect is the departure of the observed MSL from the classical $W_{0}$ geoid (e.g., Ekman and Mäkkinen, 1991; Ekman, 1994). This departure is due to the SSTop (cf. land topography), which combines the [time-averaged] effects of changes in seawater temperature, salinity, atmospheric pressure, prevailing winds and water currents (e.g., ocean circulation). SSTop causes the mean sea surface to depart from the classical geoid by as much as $2 \mathrm{~m}$ in the open oceans (e.g., Rapp, 1983; 1994; 1995; Mitchell, 1973c). Moreover, accurate determination of the SSTop becomes particularly problematic in coastal areas (e.g., Merry and Vaníček 1983; Hipkin, 2000), where, for instance, the outflow of freshwater from estuaries causes further departure from the classical geoid. Most tide-gauges used for a local vertical datum are located in or near estuaries because they are also used to monitor tides for shipping clearances. Other non-SSTop effects include irregular increases in sea level due to storm surges.

The combination of time-limited observation of the full tidal signature, SSTop and other related factors mean that tide-gauge observations of MSL do not coincide with the classical equipotential $W_{0}$ geoid at that point. Moreover, this offset varies as a function of position. Acknowledging these problems, many countries - or even continents - have adopted a single tide-gauge as the zero point for the realisation of their local vertical datum. This gives rise to offsets among various vertical datums on a global scale (e.g., Rapp, 1994; Burša et al., 2004). While this does not pose a problem when all users adopt the same [local] vertical datum, it does when trying to integrate height data from different vertical datums, which will not be considered here. In a few cases of national vertical datums (including the AHD), more than one tide-gauge is used, which causes distortions because the tide-gauge datum points refer to different levels due to the tidal aliasing and SSTop-induced offsets. This will be elaborated upon later for the AHD.

\section{Vertical Geodetic Datums Not Related to Gravity: Reference Ellipsoid}

The choice of the vertical datum for ellipsoidal heights is simpler than for the gravity-related vertical datums. However, this must not be misinterpreted as meaning that they are superior for all purposes. Once the appropriate reference ellipsoid has been chosen, the ellipsoidal vertical datum is defined point-wise by a readjustment of the then-available observations. In practice, several complementary space-geodetic techniques are used, such as in the definition of the International Terrestrial Reference Frame (ITRF) 2000 (Altamimi et al., 2002). However, local ellipsoidal height datums can be established that are tied to ITRF using GPS, 
such as the Australian National Network (e.g., Stewart, 1998), which is tied to the ITRF94 (epoch 1994.0). More recently, the ellipsoidal height datum for Australia has been set as ITRF2000 (epoch 2000.0) (Johnston, 2005 pers comm.), which differs from the Geocentric Datum Australia 1994 (GDA94) by several centimetres vertically.

As with a gravity-based vertical datum or a horizontal geodetic datum, an epoch is specified with an ellipsoidal height datum. This not only accounts for the observations used, but also accounts for changes in ellipsoidal height due to geodynamic and other effects. Once the epoch is specified, subsequent positions of the benchmarks can be predicted from the velocity vectors associated with their ITRF positions. Alternatively, a seven- or 14-parameter transformation (which is the standard seven-parameter conformal transformation with rates of change for each parameter) can be used to transform ellipsoidal heights between ellipsoidal height datums. As pointed out by Featherstone and Vaníček (1999), however, the standard seven-parameter transformation is intrinsically weak in height, so these results should be used with caution; a readjustment is preferable.

\section{Summary}

This section has summarised the practical realisation of vertical datums, where the height system is chosen first, the appropriate corrections made to the geodetic observations, the datum point(s) chosen, and then a least-squares adjustment is performed to establish a nationwide set of monumented benchmarks that point-wise define the vertical datum at a certain epoch. Users of the vertical datum then connect their measurements to these benchmarks in order to propagate heights to other points of interest, while remembering to apply the appropriate corrections to the new observations. There are some intricacies in defining the reference "surface" for the vertical datums, which mean that the point-wise practical realisations are offset from one another and distorted from a single equipotential surface of the Earth's gravity field if multiple tide-gauges are used

\section{THE AUSTRALIAN HEIGHT DATUM (AHD)}

With the above preliminaries of height systems and vertical datums complete, it is now possible to explain and discuss the AHD in a more informed sense.

\section{Height System}

The height system used in the AHD is actually a modified version of the normal-orthometric height system (e.g., Holloway, 1988), where a truncated form of Rapp's (1961) normal- 
orthometric correction was applied to the spirit-levelling observations (Roelse et al., 1975). Importantly, no gravity observations were deliberately made along the AHD spirit-levelling traverses, so the AHD is not rigorously based on a physical/natural height system. Instead, normal gravity from the GRS67 reference ellipsoid (IAG, 1967) - noting that the updated GRS80 ellipsoid (Moritz, 1980) is now the internationally adopted standard - was used to compute the truncated normal-orthometric corrections.

These truncated normal-orthometric corrections were applied to the spirit-levelled height differences, which then demonstrated improved (but non-zero, as to be expected) loopclosures, showing that even simplified gravity corrections were needed (Roelse et al., 1975). Theoretically, these loops would never close because of the high level of approximation inherent in the truncated normal-orthometric correction. Mitchell (1973a) later computed some geopotential numbers for the AHD, but obviously these were not adopted in the 1971 realisation of the AHD.

The GRS67 normal gravity used in the AHD was computed for the horizontal coordinates of the benchmarks along the levelling lines. These coordinates were often scaled from aerial photographs, and are estimated to be precise to one mile (Johnston, 2005 pers comm). We assume that they refer to the Australian Geodetic Datum 1966 (AGD66), which was the only horizontal geodetic datum in use at that time. Since GRS67 is a geocentric reference ellipsoid, geocentric coordinates must be used to compute normal gravity (cf. Featherstone, 1995). Though the ANS is the same size and shape as GRS67 (Bomford, 1967), the ANS is not a normal ellipsoid so does not generate a normal gravity field. As well as using an outdated model for normal gravity, there is a bias introduced due to the northsouth difference of $\sim 150 \mathrm{~m}$ between the AGD66 and a geocentric horizontal datum. It is acknowledged that this bias is probably small, but should be considered even if the AHD is to be redefined in terms of normal-orthometric heights. In addition, the more recent GRS80 reference ellipsoid should be used.

The imprecision of the horizontal coordinates of the AHD benchmarks will also cause problems for the future implementation of a more rigorous physical/natural height system based on observed gravity in a revised AHD. For instance, to compute Helmert orthometric corrections requires gravity at the benchmarks, and since this has not been observed, it will be necessary to interpolate values from the Australian national gravity database (Murray, 1997). The $1.7-\mathrm{km}$ (one mile) uncertainty in the benchmark locations will cause interpolation errors, especially in areas of steep horizontal gravity gradients. Alternatively, new more rigorous orthometric corrections can be computed from surrounding gravity observations, a 
digital density model and a digital elevation model (Tenzer et al., 2005; Kingdon et al., 2005), and then interpolated to the benchmarks. Of course, the current uncertainty in the horizontal position of the benchmarks will also affect this approach.

From Western Australian experience, an increasing number of existing AHD benchmarks are being upgraded in that horizontal positions are now being determined using differential GPS. As such, many are now known to between $1 \mathrm{~m}$ and $5 \mathrm{~m}$ horizontally on a geocentric datum. This will allow the improved determination of normal-orthometric corrections, as well as the interpolation of nearby gravity observations in order to implement a natural/physical height system. In addition, increasing numbers of gravity observations have been made at AHD benchmarks for geophysical surveys, which would allow the direct computation of the natural/physical heights. As such, the infrastructure is (perhaps inadvertently) being developed to allow the upgrade to a more rigorous natural/physical height system in the AHD. It is recommended that this upgrade of benchmarks be extended to all other Australian States and Territories, if it is not occurring already.

\section{Tide-gauge Observations}

As stated, MSL should be determined over the full 18.6-year luni-solar cycle. However, the 32 tide-gauges used as the zero points in the realisation of the AHD (30 on the Australian mainland and two in Tasmania) only observed MSL over a 2-3 year period (Roelse et al., 1975). As such, they are aliased by the spatially varying tidal effects. That is, the tidal range and tidal frequency content is different at each tide-gauge, thus a limited observation period cannot determine the true MSL at each. This aliasing effect is difficult to quantify, but is crudely estimated here to be as much as $10 \mathrm{~cm}$. In addition, equipment failure and noise in the tide-gauge measurements used for the AHD may cause $10-15 \mathrm{~cm}$ offsets from true MSL at each tide-gauge (Coleman et al., 1979; Mitchell, 1973b).

As well as incorrect MSL determination, tide-gauges do not directly sense the classical geoid because spatially varying SSTop and other biases act to offset the observed MSL from the classical geoid. Long-wavelength SSTop charts show that there is a general north-south trend of $\sim 1 \mathrm{~m}$ in the deep oceans around Australia (cf. Featherstone, 2001). However, this varies as a function of position and is particularly problematic in the coastal zone (e.g., Hipkin, 2000; Merry and Vaníček, 1983). Many of the tide-gauges used in the realisation of the AHD were located in or near estuaries and are thus subject to the systematic offset of MSL due to the different equipotential surface occupied by the relatively lighter freshwater, as well as the back-up of this outflow constrained by the many reefs surrounding Australia, 
notably in Queensland. These effects are also very difficult to quantify, but may reach 10-20 $\mathrm{cm}$.

Suffice it to say, there are several effects that cause the tide-gauge estimates of local MSL, which were held fixed to zero height in the 1971 realisation of the AHD, to be offset from one another and from true MSL. Therefore, even in the case of error-free natural/physical heights, they would not agree with the tide-gauge observations. This is exacerbated when the observed normal-orthometrically corrected spirit-levelling is used.

Indeed, this may have contributed to numerous studies on the apparent sea level slope (e.g., Hamon and Greig, 1972; Mitchell, 1973b; Angus-Leppan, 1975; Leppert et al., 1975; Coleman et al., 1979; Macleod et al., 1988), though it is more likely that gross levelling errors along the New South Wales and Queensland coasts were the main cause (Morgan, 1992; NMC, 1986). More importantly, fixing the tide-gauges to zero height introduces distortions of approximately $1.5 \mathrm{~m}$ in the AHD, which was recognised at the time (Roelse et al., 1975). Finally, even if only one tide-gauge had been used, then the AHD would still be offset from the classical geoid, which however is less critical because all Australian users adopt the same vertical datum.

Since the realisation of the AHD, most of the original tide-gauges have either been removed or moved vertically, usually due to equipment upgrades. Recall that we do not consider geodynamic effects, nor shall we consider changes in MSL due to the effects of global warming. As such, it is probably impossible to use these tide-gauges to determine a full 18.6-year MSL estimate. However, several new tide-gauges have now been placed under the auspices of the National Tidal Facility and as Australia's contribution to monitoring MSL in the Asia-Pacific region. As such, it may now be possible to observe the full 18.6-year lunisolar tidal cycle, albeit at other locations.

Provided that spirit-levelling observations are made to these new tide-gauges along the shortest-possible distance from the primary levelling lines of the AHD, this will permit a better determination of the tidal aliasing effect. However, as most of the original tide-gauges are missing, it will not be possible to apply this directly to the 1971 realisation of the AHD. In a future determination of the zero point of the AHD, we recommend that a single wellplaced tide-gauge that has observed the full 18.6-year tidal cycle, as well as the latest available models of the SSTop and other quantifiable biases, is used. Tide-gauge monitoring, say by GPS, should also be used to separate any vertical tide-gauge motion from the MSL estimate. 


\section{Spirit-levelling Observations}

Approximately 195,000 km of spirit-levelling observations were used in the AHD (Roelse et al., 1975). Though some first-order (Class L1A) and second-order (Class L2A) traverses were used in the adjustment, the majority of observations were to class LC tolerances. See ICSM (2002) for the Australian definitions of class of spirit-levelling observations. Morgan (1992) concluded that, overall, the AHD is a third-order datum, which reflects the 'downgrading' of the higher class observations by the lower ones.

In the least-squares adjustment of the spirit-levelled [truncated] normal-orthometric height differences, a free-net or fixed-net adjustment can be applied. Usually, a free-network adjustment is used to establish vertical datums, where one tide-gauge measurement of MSL is held fixed (minimum constrained) to zero height, thus defining the datum point. However, the AHD fixed the time-limited MSL height to zero at multiple tide-gauges. The problem that this fixed-net adjustment caused on the 1971 version of the AHD is that distortions were introduced, which was acknowledged at that time (Roelse et al., 1975).

The general north-south trend in the SSTop also explains most, but not all, of the north-south-trending departure of the AHD from gravimetric geoid models, but this is equivocal (e.g., Featherstone, 2004; Baran et al., 2005). Additional distortions remain that cannot be completely explained by the fixed-net adjustment strategy. These are most likely to be a combination of spirit-levelling errors (e.g., Angus-Leppan, 1975; Pelzer and Niemeier, 1984; Kasser and Becker, 1999), the omission of observed gravity, tidal effects on levelling, and systematic heating of the northern side of the instruments used, among others.

We are currently working on the evaluation of these effects with a view to ultimately providing a revised AHD. This also fits in with ICSM's height modernisation programme, and we will continue to work in collaboration with Geoscience Australia on this.

\section{THE AHD AND THE NATIONAL GEOID MODEL}

We have repeatedly shown that there are systematic differences between the current Australian geoid model, AUSGeoid98 (Featherstone et al., 2001), and GPS-AHD data (e.g., Featherstone and Guo, 2001; Featherstone, 2004), as well as with global geoid models (e.g., Featherstone and Stewart, 1998). Due to the separability problem of not being able to determine whether the cause is solely in the AHD or AUSGeoid98 (cf. Featherstone, 2004), this remains an open question, but there is now increasing evidence of the problem lying mostly in the AHD (Baran et al., 2005). 
It is also worth noting that AUSGeoid98 is technically more correctly termed a quasigeoid (perhaps we should have termed it Quaussiegeoid98!). This is because Molodenskian theories were embedded (albeit not completely) in its computation, and no topographic mass-density information was used. This makes it theoretically more compatible with the AHD, because a quasigeoid should be used in conjunction with normal-orthometric heights (described earlier).

However, due to the plethora of errors in both the AHD and AUSGeoid98, discrepancies remain. This requires that GPS surveyors have to routinely occupy surrounding AHD benchmarks so as to apply an additional transformation surface to account for these differences in their work area (cf. Featherstone et al., 1998). Since the ICSM has decided to retain the AHD for the "foreseeable future", it has become necessary to produce a surface for the direct transformation of GPS heights to the AHD (cf. Featherstone, 1998). This could be termed an AHDoid? Featherstone and Sproule (2005) have completed this for AUSGeoid98 using least squares collocation (LSC) prediction, as have Soltanpour et al. (2005) using second-generation wavelets. Both studies show that there is a dominant north-south difference of $1.5 \mathrm{~m}$, together with regional distortions, which sometimes correspond with the differences between the free- and fixed-network adjustments of the AHD in Roelse et al. (1975); cf. Featherstone and Stewart (1998).

As geoid determination theories and source data continue to improve, notably with the GRACE (Gravity Recovery And Climate Experiment) and GOCE (Gravity field and steadystate Ocean Circulation Explorer) dedicated satellite gravimetry missions, the problems in the AHD will become more apparent. Rummel et al. (2002) postulate that the combination of these missions will deliver $1 \mathrm{~cm}$ geoid models for distances greater than $100 \mathrm{~km}$. However, one has to be careful not to be misled that, because we are now forced to use the surfacefitting technique, there are no problems in the AHD. Instead, the surface fitting only serves to mask the errors in the AHD.

Instead, we recommend that the AHD is redefined and readjusted, probably with the inclusion of improved GPS and gravimetric quasigeoid/geoid data and making use of new levelling, horizontal coordinates and gravity observations along the levelling lines, so as to define a theoretically more rigorous vertical datum for Australia.

\section{CONCLUDING REMARKS}

This paper has briefly reviewed the concepts of height systems and vertical datums, without mathematical detail. Given this background, it has been possible to discuss some of the 
physical-geodetic intricacies of the AHD. The distortions in the AHD are causing problems in that improved gravimetric quasigeoid models are now revealing the fundamental inconsistencies between these two vertical reference surfaces, to the point at which GPS surveys are incompatible with the AHD. Until the AHD is redefined and readjusted, it has become necessary to warp the gravimetric quasigeoid model to better fit the AHD. These procedures will be used in the next release of AUSGeoid, but these authors remain firm proponents of a redefined AHD.

\section{Acknowledgements}

This work is funded by Australian Research Council grant DP0211827 to Featherstone. We would like to thank the two anonymous reviewers and editors for pointing out clarifications.

\section{REFERENCES}

Allister, N.A. and Featherstone, W.E. (2001) Estimation of Helmert orthometric heights using digital barcode levelling, observed gravity and topographic mass-density data over part of the Darling Scarp, Western Australia, Geomatics Research Australasia, no. 75, pp. 25-52.

Altamimi, Z., Sillard, P. and Boucher, C. (2002) ITRF2000: a new release of the International Terrestrial Reference Frame for Earth science applications, Journal of Geophysical Research - Solid Earth, vol. 107, no. B10: 2214, doi: 10.1029/2001JB000561

Amos, M.J., Featherstone, W.E. and Blick, G.H. (2005) Progress towards implementation and development of a New Zealand national vertical datum, in: Sansò, F. (ed.) A Window on the Future of Geodesy, Springer, Berlin Heidelberg New York, pp. 338-343.

Angus-Leppan, P.V. (1975) An investigation of possible systematic errors in levelling along the eastern coast of Australia, UNISURV Report G-23, School of Surveying, University of New South Wales, Sydney, Australia, pp. 80-91.

Balasubramania, N. (1994) Definition and realization of a global vertical datum, Report No. 427, Department of Geodetic Science and Surveying, The Ohio State University, Columbus, USA, $112 \mathrm{pp}$.

Baran, I., Kuhn, M., Claessens, S.J., Featherstone, W.E., Holmes, S.A. and Vaníček, P (2005) A synthetic Earth gravity model designed specifically for testing regional gravimetric geoid determination algorithms, Journal of Geodesy, vol. 79 (in press)

Benciolini, B., Baldi, P., Sacerdote, F. and Sansò, F. (2001) The height datum problem: the Italian case, International Geoid Service Bulletin, no. 11, pp. 118-136.

Biró, P. (1983) Time Variation of Height and Gravity, Wichmann, Karlsruhe, 160 pp.

Bomford, A.G. (1967) The geodetic adjustment of Australia, 1963-1966. Survey Review, vol. XIX, no. 144, pp. 52-71

Bomford, G. (1980) Geodesy, fourth edition, Oxford University Press, 700 pp.

Christie, R.R. (1994) A new national heighting strategy for Great Britain, Survey Review, vol. 32 , no. 252 , pp. $328-343$ 
Burša, M., Kenyon, S., Kouba J., Síma Z., Vatrt, V. and Vojtiskova, M. (2004) A global vertical reference frame based on four regional vertical datums, Studia Geophysica et Geodaetica vol. 48, no. 3, pp. 493-502

Coleman, R., Rizos, C., Masters, E.G. and Hirsch, B. (1979) The investigation of the seasurface slope along the north-eastern coast of Australia, Australian Journal of Geodesy, Photogrammetry and Surveying, no. 31, pp. 65-99.

Colombo, O.L. (1980) A world vertical network, Report 296, Department of Geodetic Science and Surveying, The Ohio State University, Columbus, USA

Dennis, M.L. and Featherstone, W.E. (2003) Evaluation of orthometric and related height systems using a simulated mountain gravity field, in: Tziavos, I.N. (ed) Gravity and Geoid 2002, Department of Surveying and Geodesy, Aristotle University of Thessaloniki, Greece, pp. 389-394

Ekman, M. (1989) Impacts of geodynamic phenomena on systems of height and gravity, Bulletin Géodésique, vol. 63, no. 2, pp. 281-296

Ekman, M. (1994) Deviation of mean sea level from the mean geoid in the transition area between the North Sea and the Baltic Sea, Marine Geodesy, vol. 17, no. 2, pp. 161-168

Ekman, M. and Mäkkinen, J. (1991) The deviation of mean sea level from the mean geoid in the Baltic Sea, Bulletin Géodésique, vol. 65, no. 1, pp. 83-91

Featherstone, W.E. (1995) On the use of Australian geodetic datums in gravity field determination, Geomatics Research Australasia no. 62, pp. 17-36

Featherstone, W.E. (1996) An updated explanation of the Geocentric Datum of Australia and its effects upon future mapping, The Australian Surveyor vol. 41, no. 2, pp. 121-130

Featherstone, W.E. (1998) Do we need a gravimetric geoid or a model of the base of the Australian Height Datum to transform GPS heights? The Australian Surveyor, vol. 43, no. 4 , pp. $273-280$

Featherstone, W.E. (2000) Towards unification of the Australian height datum between the Australian mainland and Tasmania using GPS and the AUSGeoid98 geoid model, Geomatics Research Australasia, no. 73, pp. 33-54

Featherstone, W.E. (2001) Prospects for the Australian Height Datum and geoid model, in: Adam, J. and Schwarz, K-P. (eds) Vistas for Geodesy in the New Millennium, Springer, Berlin Heidelberg New York, pp. 96-101

Featherstone, W.E. (2002a) Attempts to unify the Australian Height Datum between the mainland and Tasmania, in: Drewes, P., A. Dodson, L.P. Fortes, L. Sanchez and P. Sandoval (eds) Vertical Reference Systems, Springer, Berlin Heidelberg New York, pp. $328-333$

Featherstone, W.E. (2002b) Expected contributions of dedicated satellite gravity field missions to regional geoid determination with some examples from Australia, Journal of Geospatial Engineering vol. 4, no. 1, pp. 1-19

Featherstone, W.E. (2004) Evidence of a north-south trend between AUSGeoid98 and the AHD in southwest Australia, Survey Review, vol. 37, no. 291, pp. 334-343

Featherstone W.E, and Guo, W. (2001) A spatial evaluation of the precision of AUSGeoid98 versus AUSGeoid93 using GPS and levelling data, Geomatics Research Australasia, no. 74, pp. 75-102 
Featherstone, W.E. and Kirby, J.F. (1998) Estimates of the separation between the geoid and quasi-geoid over Australia, Geomatics Research Australasia, no. 68, pp. 75-86

Featherstone, W.E. and Sproule, D.M. (2005) Fitting AUSGeoid98 to the Australian Height Datum using GPS data and least squares collocation: application of a cross-validation technique, Survey Review (in press)

Featherstone W.E. and Stewart, M.P. (1998) Possible evidence for systematic distortions in the Australian Height Datum in Western Australia, Geomatics Research Australasia, no. 69, pp. $1-14$

Featherstone, W.E. and Vaníček, P. (1999) The role of coordinate systems, coordinates and heights in horizontal datum transformations, The Australian Surveyor, 44(2): 143-150. [Correspondence in The Australian Surveyor, 45(1): 5-11 and The Trans-Tasman Surveyor, 1(3): 5-7]

Featherstone, W.E., Dentith, M.C. and Kirby, J.F. (1998) Strategies for the accurate determination of orthometric heights from GPS, Survey Review, vol. 34, no.267, pp 278296.

Featherstone, W.E., J.F. Kirby, A.H.W. Kearsley, J.R. Gilliland, G.M. Johnston, J. Steed, R. Forsberg, M.G. Sideris (2001) The AUSGeoid98 geoid model of Australia: data treatment, computations and comparisons with GPS-levelling data, Journal of Geodesy, vol. 75, nos. 5/6, pp. 313-330, doi: 10.1007/s001900100177.

Gilliland, J.R. (1986) Heights and GPS, The Australian Surveyor, vol. 33, no. 4, pp. 277-283.

Hamon, B.V. and Greig, M.A. (1972) Mean sea level in relation to geodetic land levelling around Australia, Journal of Geophysical Research vol. 77, no. 36, pp. 7157-7162

Heck, B. (1995) Rechenverfahren und Auswertemodelle der Landesvermessung, Wichman, Karlsruhe, Germany, 470 pp

Heck, B. and Rummel, R. (1989) Strategies for solving the vertical datum problem using terrestrial and satellite geodetic data, in: Sünkel, H. and T. Baker (eds) Sea-surface Topography and the Geoid, Springer, Berlin Heidelberg New York, pp. 116-128.

Heiskanen, W.A. and Moritz, H. (1967) Physical Geodesy, WH Freeman \& Co, San Francisco, USA, 364 pp.

Helmert, F. R. (1890) Die Schwerkraft im Hochgebirge, Insbesondere in den Tyroler Alpen. Veroff. Konigl. Preuss., Geod. Inst., No. 1

Helmert, F.R. (1884) Die Mathematischen und Physikalischen Theorien der Höheren Geodäsie., Teubner, Leipzig, 610 pp (re-printed by Minerva, Frankfurt, 1962)

Hipkin, R.G. (2000) Modelling the geoid and sea-surface topography in coastal areas, Physics and Chemistry of the Earth - Series A, vol. 25, no. 1, pp. 9-16.

Holloway, R.D. (1988) The integration of GPS heights into the Australian Height Datum, UNISURV Report S33, School of Surveying, The University of New South Wales, Sydney, Australia, $151 \mathrm{pp}$.

IAG (1967) Geodetic reference system 1967, Special Publication 3, Bulletin Géodésique, International Association of Geodesy, Paris, France, 116 pp.

ICSM (2002) Standards and Practices for Control Surveys (version 1.5), Inter-Governmental Committee on Surveying and Mapping, Canberra, Australia, [http://www.icsm.gov.au/icsm/publications/sp1/sp1.htm] 
Jekeli, C. (1999) An analysis of vertical deflections derived from high-degree spherical harmonic models, Journal of Geodesy, vol. 73, no. 1, pp. 10-22, doi: $10.1007 / \mathrm{s} 001900050213$

Jekeli, C. (2000) Heights, the geopotential, and vertical datums, Report 459, Department of Geodetic Science, The Ohio State University, Columbus, USA, 34 pp.

Johnston, G.M. (2005) personal communication, Project Manager, Geoscience Australia.

Johnston, G.M. and Luton, G.C. (2001) GPS and the Australian Height Datum, Proceedings of the Fifth International Symposium on Satellite Navigation Technology and Applications, Kubik, K., Rizos, C. and Featherstone, W.E. (eds), Canberra, Australia, July, [CD-ROM]

Kasser, M. and Becker, J-M. (1999) Error sources in high precise levelling - how to minimise their effects on the heights, Proceedings of Geodesy and Surveying in the Future: The Importance of Heights, Lilje, M. (ed), LMV Report 1999:3, National Land Survey, Gävle, Sweden, pp. 213-221.

Kearsley, A.H.W., Ahmed, Z. and Chan, A. (1993) National height datums, levelling, GPS heights and geoids, Australian Journal of Geodesy Photogrammetry and Surveying, no. 59, pp. 53-88

Kearsley, A.H.W., Rush, G.J. and O’Donell, P.W. (1988) The Australian Height Datum problems and proposals, The Australian Surveyor, vol. 34, no. 4, pp. 363-380

Kingdon, R., Vaníček, P., Santos, M., Ellmann, A. and Tenzer, R. (2005) Toward an improved orthometric height system for Canada, Geomatica, vol. 59 (in press)

Kumar, M. (2005) When ellipsoidal heights will do the job, why look elsewhere! Surveying and Land Information Science, vol. 65, no. 2, pp.

Kumar, M. and Burke, K.J. (1998) Realizing a global vertical datum with the use of geoid, in: Vermeer, M. and J. Ádám (eds) Proceedings of the Second Continental Workshop on the Geoid in Europe, Report 98:4, Finnish Geodetic Institute, Masala, Finland, pp. 8794

Leppert, K. (1967) Problems encountered in the use of third order levelling for the national levelling grid, in: Angus-Leppan, P.V. (ed) Control for Mapping by Geodetic and Photogrammetric Methods, The University of New South Wales, Sydney, Australia, pp. 123-134

Leppert, K., Hamon, B.V. and Mather, R.S. (1975) A status report on investigations of sea surface slope along the eastern coast of Australia, UNISURV Report G-23, School of Surveying, University of New South Wales, Sydney, Australia, pp. 60-67.

Lines, J.D. (1992) Australia on Paper - The Story of Australian Mapping, Fortune Publications, Box Hill, Australia

Macleod, R.T., Kearsley, A.H.W. and Rizos, C. (1988) GPS surveys of mean sea-level along the New South Wales coastline, Australian Journal of Geodesy, Photogrammetry and Surveying, no. 49, pp. 39-53.

Mader, K. (1954) Die orthometrische Schwerekorrektion des Präzisions-Nivellements in den Hohen Tauern (The orthometric weight correction of precision levelling in high terrain), Österreichische Zeitschrift für Vermessungswesen, Sonderheft 15, Vienna

Melchior, P. (1981) The Tides of the Planet Earth. Pergamon Press, Oxford, England, 655 pp. 
Merry, C., and Vaníček, P. (1983) Investigation of local variations of sea surface topography, Marine Geodesy, vol. 7, no. 2, pp. 101-126.

Meyer, T.H., D.R. Roman and D.B. Zilkoski (2004) What does height really mean? Part I: Introduction, Surveying and Land Information Science, vol. 64, no. 4, pp. 223-233.

Meyer, T.H., D.R. Roman and D.B. Zilkoski (2005) What does height really mean? Part II: Physics and gravity, Surveying and Land Information Science, vol. 65, no. 1, pp. 5-15

Mitchell, H.L. (1973a) An Australian geopotential network based on observed gravity, UNISURV Report G18, School of Surveying, University of New South Wales, Sydney, Australia, 80pp.

Mitchell, H.L. (1973b) Relations between mean sea level and geodetic levelling in Australia, UNISURV Report S9, School of Surveying, University of New South Wales, Sydney, Australia, $277 \mathrm{pp}$.

Mitchell, H.L. (1973c) Sea-surface topography in geodesy with particular reference to Australia, Proceedings of the Symposium on the Earth's Gravitational Field and Secular Variations in Position, The University of New South Wales, Sydney, Australia, pp. 573584.

Mitchell, H.L. (1988) GPS heighting in Australia: an introduction, The Australian Surveyor, vol. 34 , no. 1 , pp. 5-10

Mitchell, H.L. (ed) (1990) Heighting with the Global Positioning System in Australia: the current situation. Report of the GPS Heighting Study Group of the Australian GPS Users Group

Molodensky, M., Yeremeyev, V. and Yurkina, M. (1962) Methods for Study of the External Gravitational field and Figure of the Earth, Israeli Program for Scientific Translations, Jerusalem, pp.

Morgan, P.J. (1992) An analysis of the Australian Height Datum: 1971, The Australian Surveyor, vol. 37, no. 1, pp. 46-63

Moritz, H. (1980) Geodetic reference system 1980, Bulletin Géodésique, vol. 54, no. 4, pp. $395-405$

Moritz, H. (1992) The Figure of the Earth: Theoretical Geodesy and the Earth's Interior, Wichmann, Karlsruhe, Germany, 279 pp

Murray, A. (1997) The Australian national gravity database, AGSO Journal of Australian Geology \& Geophysics, vol 17, no. 1, pp. 145-155

NGS (1998) National Height Modernization Study: Report to Congress, National Geodetic Survey, Rockville, Maryland, USA, 181 pp. http://www.acsm.net/heightmod.pdf

Niethammer, T. (1932) Nivellement und Schwere als Mittel zur Berechnung wahrer Meereshöhen (Levelling and weight as a means for the computation of true sea level heights), Schweizerische Geodätische Kommission, Berne, 76 pp

NIMA (2004) Department of Defense World Geodetic System 1984: Its Definition and Relationships With Local Geodetic Systems, third edition with revisions, Technical Report TR8350.2, National Imagery and Mapping Agency, Maryland, USA http://earthinfo.nga.mil/GandG/publications/tr8350.2/tr8350_2.html

NMC (1986) Australian Geodetic Datum Technical Manual, Special Publication 10, National Mapping Council, Canberra, Australia, 62 pp 
Pelzer, H. and Niemeir, W. (eds) (1984) Precise Levelling, Dümmler, Bonn, Germany, 490 pp.

Pouttanen, M. (1999) Use of GPS in unification of vertical datums and detection of levelling network errors, Proceedings of Geodesy and Surveying in the Future: The Importance of Heights, Lilje, M. (ed), LMV Report 1999:3, National Land Survey, Gävle, Sweden, pp. 301-312

Rapp R.H. and N. Balasubramania (1992) A conceptual formulation of a world height system, Report 421, Department of Geodetic Science and Surveying, The Ohio State University, Columbus, USA

Rapp, R.H. (1961) The orthometric height, M.S. Thesis, Department of Geodetic Science, The Ohio State University, Columbus, USA, $117 \mathrm{pp}$

Rapp, R.H. (1983) The need and prospects for a world vertical datum, Proceedings of the International Association of Geodesy Symposia, Vol, 2, International Union of Geodesy and Geophysics XVIII General Assembly, Hamburg, Germany, pp. 432-445

Rapp, R.H. (1994) Separation between reference surfaces of selected vertical datums, Bulletin Géodésique, vol. 69, no. 1, pp. 26-31

Rapp, R.H. (1995) A world vertical datum proposal, Allgemeine Vermessungs-Nachrichten, vol. 102 , nos. 8-9, pp. 297-304

Rapp, R.H. (1997) Use of potential coefficient models for geoid undulation determinations using a spherical harmonic representation of the height anomaly/geoid undulation difference, Journal of Geodesy, vol. 71, no. 5, pp. 282-289, doi: $10.1007 / \mathrm{s} 001900050096$

Rizos, C., Coleman, R. and Ananga, N. (1991) The Bass Strait GPS survey: preliminary results of an experiment to connect Australian height datums, Australian Journal of Geodesy, Photogrammetry and Surveying, no. 55, pp. 1-25

Roelse A., Granger, H.W. and Graham, J.W. (1975) The adjustment of the Australian levelling survey 1970 - 1971, second edition, Technical Report 12, Division of National Mapping, Canberra, Australia, $81 \mathrm{pp}$

Rummel, R. and Ilk, K-H. (1995) Height datum connection - the ocean part, Allgemeine Vermessungs-Nachrichten, vol. 102, nos. 8-9, pp. 321-330

Rummel, R. and Teunissen, P.J.G. (1988) Height datum definition, height datum connection and the role of the geodetic boundary value problem, Bulletin Géodésique, vol. 62, no. 4, pp. 477-498

Rummel, R., Balmino, G., Johannessen, J., Visser, P.N.A.M. and Woodworth, P. (2002) Dedicated gravity field missions - principles and aims, Journal of Geodynamics, vol. 33, no. 1 , pp. $3-20$

Sansò, F. and Vaníček, P. (2005) The orthometric height and the holonomity problem, Journal of Geodesy 79 (in press)

Soltanpour, H., Nahavandchi, H. and Featherstone, W.E. (2005) On the use of secondgeneration wavelets to combine a gravimetric geoid model with GPS-levelling data, Journal of Geodesy (submitted)

Steed, J. and Holtznagel, S. (1994) AHD heights from GPS using AUSGEOID93, The Australian Surveyor, vol. 39, no. 1, pp. 21-27. 
Steinberg, G. and Papo, H. (1998) Ellipsoidal heights: the future of vertical geodetic control, GPS World, vol 9, no. 2, pp. 41-43.

Stewart, M.P. (1998) How accurate is the Australian National GPS Network as a framework for GPS heighting?, The Australian Surveyor, vol. 43, no. 1, pp. 53-61.

Strange, W.E. (1982) An evaluation of orthometric height accuracy using borehole gravimetry, Bulletin Géodésique vol. 56, no. 4, pp. 300-311

Sünkel, H. (1986) Digital height and density model and its use for the orthometric height and gravity field determination for Austria, Proceedings of the International Symposium on the Definition of the Geoid, Florence, Italy, May, pp. 599-604

Tapley, B.D., Bettadpur, S., Watkins, M. and Reigber, C. (2004) The gravity recovery and climate experiment: mission overview and early results, Geophysical Research Letters 31, L09607

Tenzer, R., Vaníček, P., Santos, M., Featherstone, W.E. and Kuhn, M. (2005) Rigorous determination of the orthometric height, Journal of Geodesy, vol. 79, nos 1-3, doi: $10.1007 / \mathrm{s} 00190-005-0445-2$

Torge, W. (2001) Geodesy, third edition, Walter de Gruyter, Berlin New York, 416 pp

van Olsen, K. and van Gelderen, M. (1998) Quality investigation of the vertical height datum connection, Physics and Chemistry of the Earth - Series A, vol. 23, nos. 9-10, pp. 11031108

Vaníček, P. (1991) Vertical datum and NAVD88, Surveying and Land Information Systems, vol. 51, no. 2, pp. 83-86

Vaníček, P. (1998) The height of reason, GPS World, vol. 9, no. 4, pp. 14.

Vaníček, P. and Krakiwsky, E.J. (1986) Geodesy: The Concepts, second edition, Elsevier, Amsterdam, Holland

Véronneau, M., Pagiatakis, S.D. and Mainville, A. (2001) The Canadian vertical datum: a new perspective for the year 2005 and beyond, in: Sideris M.G. (ed) Geodesy, Gravity \& Geoid 2000, Springer, Berlin Heidelberg New York, pp.

$\mathrm{Xu}, \mathrm{P}$. (1992) A quality investigation of global vertical datum connection, Geophysical Journal International, vol. 110, no. 2, pp. 361-370.

Zilkoski, D. (2001) Vertical datums, Digital elevation model technologies and applications: The DEM users manual, Maune, D.F. (ed.), American Society for Photogrammetry and Remote Sensing, Bethesda, Maryland, USA, pp. 35-60 